\title{
Pulse duration measurements of grazing-incidence-pumped high repetition rate Ni-like Ag and Cd transient soft $x$-ray lasers
}

\author{
M. A. Larotonda, Y. Wang, M. Berrill, B. M. Luther, and J. J. Rocca \\ NSF Center for Extreme Ultraviolet Science and Technology, Colorado State University, Fort Collins, \\ Colorado 80523 \\ Mahendra Man Shakya, S. Gilbertson, and Zenghu Chang \\ Department of Physics, J. R. MacDonald Laboratory, Kansas State University, Manhattan, Kansas 66506
}

Received June 6, 2006; accepted July 5, 2006;

posted July 27, 2006 (Doc. ID 71706); published September 25, 2006

We have measured the pulse duration of gain-saturated $13.9 \mathrm{~nm}$ Ni-like Ag and $13.2 \mathrm{~nm}$ Ni-like Cd transient collisional lasers excited by grazing-incidence-pumping for several pumping conditions. Highresolution streak-camera measurements yielded FWHM pulse durations close to $5 \mathrm{ps}$ for both lasers under optimum pumping conditions. The very high brightness and short pulse duration of these new high repetition tabletop soft x-ray lasers make them an attractive source for dynamic applications. (C) 2006 Optical Society of America

OCIS codes: $140.7240,340.7480$.

There is much interest in the development of high brightness sources of coherent soft x-ray radiation for applications. Electron-collision-excited x-ray lasers offer the possibility of generating high-energy pulses of coherent short wavelength light of very high brightness and short pulse duration, but have been mostly limited to very low repetition rates. Recent experiments using a grazing-incidence-pumping configuration have achieved saturated laser operation at a $5 \mathrm{~Hz}$ repetition rate for wavelengths as short as $13.2 \mathrm{~nm} \cdot{ }^{1-4}$ With average powers at the microwatt level, ${ }^{3,4}$ these new compact transient collisional lasers are of significant interest for static and dynamic applications. However, the latter require good knowledge of the laser pulse duration. In this Letter, we report what is, to the best of our knowledge, the first experimental measurement of their pulse duration.

The earliest collisional soft $\mathrm{x}$-ray lasers were excited by nanosecond duration high-energy optical laser pulses from kilojoule-class lasers. ${ }^{5}$ Producing quasi-steady-state population inversions in Ne-like and Ni-like ions, these lasers generated soft x-ray laser pulses with a duration of a few hundred picoseconds with typically hour-long intervals between pulses. The use of fast capillary discharge excitation has produced soft x-ray pulses of $\sim 1 \mathrm{~ns}$ in duration at repetition rates up to $10 \mathrm{~Hz} .{ }^{6}$ Laser-pumped soft $\mathrm{x}$-ray lasers generated by rapid heating of a precreated plasma with intense optical laser pulses of a picosecond duration impinging at near-normal incidence produced large transient inversions and reduced the pump energy requirement to $3-10 \mathrm{~J} .^{7,8} \mathrm{~A}$ few measurements of the pulse duration of these lasers have been recently conducted. ${ }^{9-11}$ FWHM pulse durations of 2-4 ps were reported for the $13.9 \mathrm{~nm}$ Ni-like Ag lasers pumped by $1.2-1.3 \mathrm{ps}$ duration Nd:glass laser pulses. ${ }^{9,10}$ Another experiment mea- sured pulse durations of $4-8 \mathrm{ps}$ for a Ni-like $\mathrm{Pd}$ $14.7 \mathrm{~nm}$ laser pumped with Nd:glass pulses of 0.5-27 ps duration. ${ }^{11}$

However, the substantial laser pump energy required for gain-saturated operation of these lasers has limited their repetition rate to typically one shot every several minutes, which results in very low average powers. Soft x-ray lasers with a picosecond pulse duration have also been obtained with lower pump energy $(330 \mathrm{~mJ})$ in plasmas created by optical field ionization, ${ }^{12}$ but to date, these lasers have been limited to wavelengths longer than $30 \mathrm{~nm}$. Recent experiments have demonstrated that the pump energy required to obtain large gain can be greatly reduced by directing the picosecond pump pulse at a grazing angle of incidence to the target surface. This pumping configuration takes advantage of the refraction of the pump beam to preferentially heat a selected region of the precreated plasma with optimum density for soft x-ray amplification. ${ }^{1-4}$ By increasing the path length of the rays in the gain region of the plasma, it increases the fraction of the pump energy absorbed in that region. This pumping geometry is inherently a traveling wave, with a traveling wave pump speed $\nu=c / \cos \theta$ (e.g., $\nu=1.09 c$ at $\left.\theta=23^{\circ}\right)$. The use of $1 \mathrm{~J}$ heating pulses at angles of incidence between $14^{\circ}$ and $23^{\circ}$ resulted in the demonstration of gain-saturated $5 \mathrm{~Hz}$ repetition rate lasers at wavelengths as short as $13.2 \mathrm{~nm}$ for Ni-like Cd. ${ }^{2-4}$

We used a high-resolution streak camera ${ }^{13}$ to measure the laser pulses generated, exciting the $4 d{ }^{1} S_{0}$ $\rightarrow 4 p{ }^{1} P_{1}$ transitions of Ni-like $\mathrm{Ag}$ and $\mathrm{Cd}$ for the optimum pumping conditions at $23^{\circ}$ grazing incidence. The experimental layout used to obtain the measurement is schematically illustrated in Fig. 1 . The soft $\mathrm{x}$-ray laser pulses were generated by heating $4 \mathrm{~mm}$ long polished slab targets of the lasing material $(\mathrm{Ag}$ 


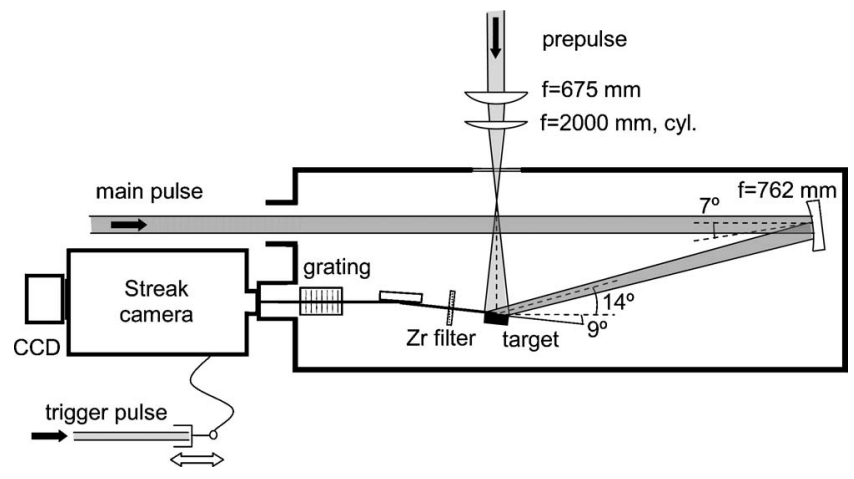

Fig. 1. Experimental setup, showing the soft x-ray laser pumping configuration and streak-camera detection system.

or Cd) with a sequence of optical laser pulses generated with a $10 \mathrm{~Hz}$ tabletop chirped-pulse amplification Ti:sapphire laser system consisting of a Kerr mode-locked oscillator and three amplification stages. The $\sim 2 \mathrm{~J}, 120 \mathrm{ps}$ output pulse of the last amplification stage is split in two, at a $20 \% / 80 \%$ ratio. The largest fraction is sent to a vacuum grating compressor, where it is compressed to create $\sim 1 \mathrm{~J}$ pulses with a selected pulse width of a few picoseconds duration. Approximately $350 \mathrm{~mJ}$ are kept uncompressed and are focused onto the target at nearnormal incidence to form a $4.1 \mathrm{~mm}$ long $\times 30 \mu \mathrm{m}$ wide line. This prepulse, which forms a plasma that is allowed to expand to reduce the density gradient, is preceded in $5.6 \mathrm{~ns}$ by an $\sim 10 \mathrm{~mJ}$ prepulse that enhances the soft x-ray laser output. Following a selected time delay of a few hundred picoseconds, the plasma is rapidly heated by the compressed picosecond pulse that is made to impinge at a grazing incidence angle of $23^{\circ}$. This short pulse is focused into a line focus of the same size utilizing an $f=76.2 \mathrm{~cm}$ parabolic mirror placed at $7^{\circ}$ from normal incidence.

The plasma emission was filtered with a $1500 \AA$ thick Zr film and was reflected at the grazing incidence by a borosilicate flat that directed it toward a $1200 \mathrm{l} / \mathrm{mm}$ gold-coated variably spaced ruling spherical grating. The grating dispersed the light and sent the laser beam to the streak-camera slit. The fast streak camera used in the experiment is described in Ref. 13. The experiments were conducted by using a 1019 A thick KBr photocathode film deposited onto a $1085 \AA$ thick lexan film. We used high harmonic pulses from a Ti:sapphire laser of less than $30 \mathrm{fs} d u-$ ration to determine the resolution of the streak camera at the $(-7 \mathrm{kV})$ photocathode acceleration voltages we used in this experiment. The resolution was determined to be $(1.8 \pm 0.1) \mathrm{ps}$. The temporal smearing produced by the grating can further degrade the resolution of the measurements. ${ }^{9,11}$ However, since the slit of the streak camera was placed $13 \mathrm{~cm}$ away from the image plane of the grating, its $25 \mu \mathrm{m}$ width sampled only a fraction of the wavefront, causing a negligible temporal smearing of $0.04 \mathrm{ps}$. The streakcamera sweep was synchronized with the soft x-ray laser using a photoconductor switch triggered with a $0.2 \mathrm{~mJ}, 50 \mathrm{fs}$ duration Ti:sapphire laser pulse generated by a chirp-pulse amplification multipass ampli- fier seeded by the same laser oscillator that seeds the soft x-ray laser pump beam. The photoconductive switch was mounted on a translation stage in order to control the delay between the sweep of the ramp and the arrival of the soft x-ray laser. The laser intensity reaching the photocathode was attenuated by slightly misaligning the center of the laser line generated by the grating with respect to the center of the slit until space charge broadening had no appreciable effect on the measurements. This was verified by observing that the pulse width remained constant as the intensity was further reduced.

Figure 2 shows a typical single streak measurement of the Ni-like Ag laser pulse for a short pump pulse of $6.7 \mathrm{ps}$ duration and a time delay of $250 \mathrm{ps}$ between the $350 \mathrm{~mJ}$ prepulse and the short pulse, pumping conditions that are nearly optimum for maximum soft $\mathrm{x}$-ray laser output pulse energy generation. The left image shows a horizontal streak of the laser pulse. Each dot on the CCD image of the camera's phosphor screen is the result of a single photoelectron amplified on the internal multichannel plate. The curve on the center panel is the corresponding temporal profile of the x-ray laser, obtained by vertical integration of the image. An average of the six shots gives a measured FWHM trace width of $(4.9 \pm 1.0)$ ps, shown in Fig. 2(c). The true laser pulse duration can be estimated to be $(4.6 \pm 1.0)$ ps by deconvolution of the instrument smearing assuming a quadrature relationship. This soft x-ray pulse duration did not vary significantly and remained within the error of the measurement when the duration of the short pump pulse was reduced to $2.0 \mathrm{ps}$. The deconvoluted laser pulse duration for this case was $(5.1 \pm 0.8) \mathrm{ps}$. The pulse duration of the Ni-like Ag $\mathrm{x}$-ray laser was also measured as a function of delay between the prepulse and the short pump pulse, along the full range of operation of the laser. ${ }^{3}$ Figure 3 shows that the laser pulse duration remains relatively constant for time delays between approximately 150 and $450 \mathrm{ps}$, but it decreases outside this

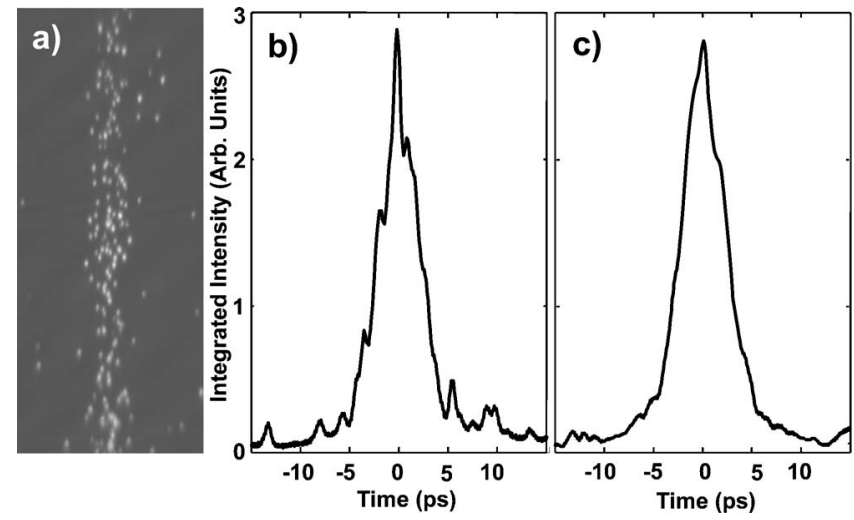

Fig. 2. (a) Single-shot streak-camera image of the $13.9 \mathrm{~nm}$ laser pulse. (b) Lineout of the integrated laser line intensity versus time. (c) Average corresponding to six laser shots. The measured FWHM width is $4.9 \mathrm{ps}$, and corresponding estimated true laser pulse duration is $4.6 \mathrm{ps}$. The laser was excited by a $6.7 \mathrm{ps}$ duration pump pulse of $1 \mathrm{~J}$ energy impinging at a grazing incidence angle of $23^{\circ}$ with a prepulse to a short pulse time delay of $250 \mathrm{ps}$. 


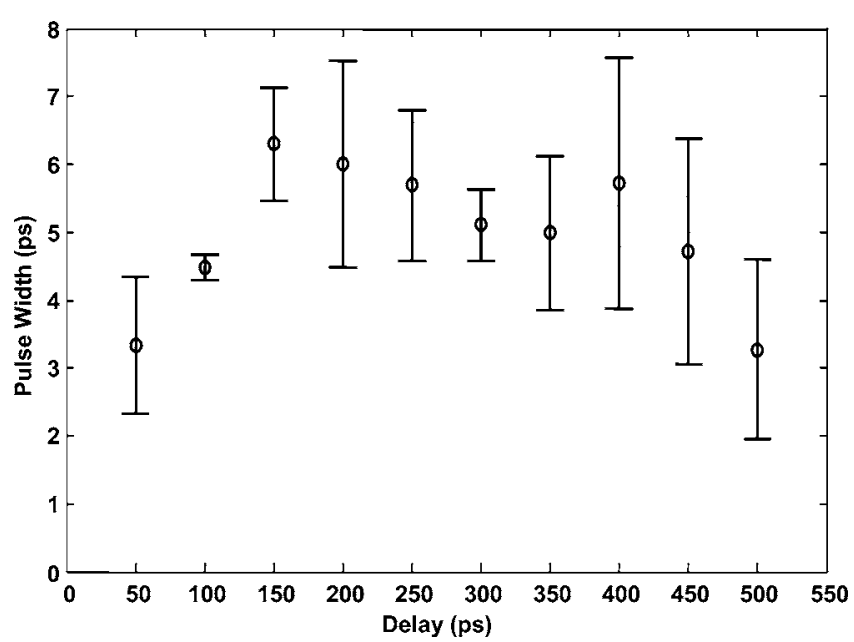

Fig. 3. Measured variation of the $13.9 \mathrm{~nm} \mathrm{Ni-like} \mathrm{Ag} \mathrm{laser}$ pulse width as a function of time delay between the $350 \mathrm{~mJ}$ prepulse and the $1 \mathrm{~J}, 6.7 \mathrm{ps}$ pump pulse.
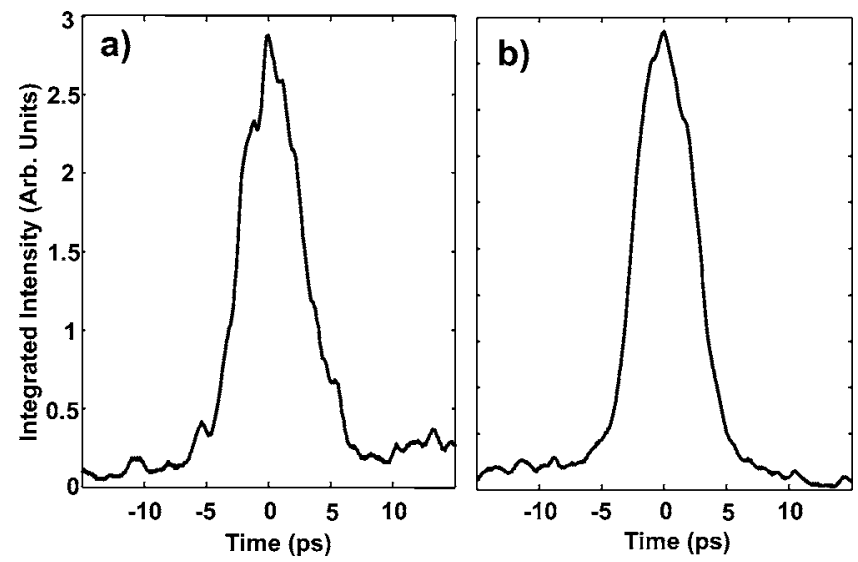

Fig. 4. (a) Lineout of a single-shot streak measurement of the $13.2 \mathrm{~nm}$ Ni-like Cd soft x-ray laser pulse. (b) Six laser shots average, showing a deconvoluted FWHM pulse duration of $5.2 \mathrm{ps}$. The laser was excited by a $6.7 \mathrm{ps}$ duration pump pulse of $1 \mathrm{~J}$ energy impinging at a grazing incidence angle of $23^{\circ}$ for a prepulse to short pulse time delay of $100 \mathrm{ps}$.

range as a result of a shorter duration of the gain for nonoptimum delays. Model computations conducted with a hydrodynamic-atomic physics model developed in-house show a gain duration of $\sim 15 \mathrm{ps}$ for Nilike $\mathrm{Ag}$ excited at the optimum pumping conditions. The exponential amplification of the spontaneous emission is computed to decrease the laser pulse duration down to $\sim 5 \mathrm{ps}$, followed by saturation rebroadening up to $9 \mathrm{~ns}$. In the experiment, the pulse rebroadening is less significant, because the laser is not as deeply saturated as in the simulation.

We also measured a similar laser pulse duration for the $13.2 \mathrm{~nm}$ Ni-like Cd grazing-incidence x-ray laser. Figure 4(a) shows a single-shot temporal profile, and Fig. 4(b) shows the average of six streak-camera traces for the near optimum short pump pulse of $6.7 \mathrm{ps}$ and the time delay of $100 \mathrm{ps}$. The average measured FWHM pulse duration is $(5.5 \pm 0.3)$ ps [Fig. $4(\mathrm{~b})]$, and the deconvoluted FWHM pulse duration is
$(5.2 \pm 0.4) \mathrm{ps}$. Since from our model the linewidth of the output of these lasers after gain narrowing can be estimated to be $\Delta \nu / \nu \approx 2.5-3.0 \times 10^{-5}$, for the measured pulse duration of approximately $5 \mathrm{ps}$, we can estimate $\Delta \nu \times \Delta t \sim 3$.

In conclusion, the measurements show that Ni-like $\mathrm{Ag}$ and $\mathrm{Cd}$ transient lasers excited at grazing incidence have pulse durations of $\sim 5 \mathrm{ps}$, corresponding to laser peak powers of up to $0.1-0.2 \mathrm{MW}$. Intense picosecond duration laser pulses in the $100 \mathrm{eV}$ spectral region are available for the first time to our knowledge at a high repetition rate for applications.

This work was supported in part by the U.S. Department of Energy Chemical Sciences, Geosciences, and Biosciences Division of the Office of Basic Energy Sciences and the National Science Foundation (NSF) Center for Extreme Ultraviolet Science and Technology under NSF award EEC-0310717. M. A. Larotonda's e-mail address is mlaroton@engr.colostate.edu.

\section{References}

1. R. Keenan, J. Dunn, P. K. Patel, D. F. Price, R. F. Smith, and V. N. Shlyaptsev, Phys. Rev. Lett. 94, 103901 (2005).

2. B. M. Luther, Y. Wang, M. A. Larotonda, D. Alessi, M. Berrill, M. C. Marconi, J. J. Rocca, and V. Shlyaptsev, Opt. Lett. 30, 165 (2005).

3. Y. Wang, M. A. Larotonda, B. M. Luther, D. Alessi, M. Berrill, J. J. Rocca, and V. N. Shlyaptsev, Phys. Rev. A 72, 053807 (2005).

4. J. J. Rocca, Y. Wang, M. A. Larotonda, B. M. Luther, M. Berrill, and D. Alessi, Opt. Lett. 30, 2581 (2005).

5. D. L. Matthews, P. L. Hagelstein, M. D. Rosen, M. J. Eckart, N. M. Ceglio, A. U. Hazi, H. Medecki, B. J. Macgowan, J. E. Trebes, B. L. Whitten, E. M. Campbell, C. W. Hatcher, A. M. Hawryluk, R. L. Kauffman, L. D. Pleasance, G. Rambach, J. H. Scofield, G. Stone, and T. A. Weaver, Phys. Rev. Lett. 54, 110 (1985).

6. B. R. Benware, C. D. Macchietto, C. H. Moreno, and J. J. Rocca, Phys. Rev. Lett. 81, 5804 (1998).

7. P. V. Nickles, V. N. Shlyaptsev, M. Kalachinkov, and M. Schnurer, Phys. Rev. Lett. 78, 2748 (1997).

8. J. Dunn, Y. Li, A. L. Osterheld, J. Nilsen, J. R. Hunter, and V. N. Shlyaptsev, Phys. Rev. Lett. 84, 4834 (2000).

9. A. Klisnick, J. Kuba, D. Ros, R. Smith, G. Jamelot, C. Chenais-Popovics, R. Keenan, S. J. Topping, C. L. S. Lewis, F. Strati, G. J. Tallents, D. Neely, R. Clarke, J. Collier, A. G. MacPhee, F. Bortolotto, P. V. Nickles, and K. A. Janulewicz, Phys. Rev. A 65, 033810 (2002).

10. Y. Abou-Ali, G. J. Tallents, M. Edwards, R. E. King, G. J. Pert, S. J. Pestehe, F. Strati, R. Keenan, C. S. Lewis, S. Topping, O. Guilbaud, A. Klisnick, D. Ros, R. Clarke, D. Neely, M. Notley, and A. Demir, Opt. Commun. 215, 397 (2003).

11. J. Dunn, R. F. Smith, R. Shepherd, R. Booth, J. Nilsen, J. R. Hunter, and V. N. Shlyaptsev, in Proc. SPIE 5197, 51 (2003).

12. S. Sebban, R. Haroutunian, P. Balcou, G. Grillon, A. Rousse, S. Kazamias, T. Marin, J. P. Rousseau, L. Notebaert, M. Pittman, J. P. Chambaret, A. Antonetti, D. Hulin, D. Ross, A. Klisnick, A. Carillon, P. Jaegle, G. Jamelot, and J. F. Wyart, Phys. Rev. Lett. 86, 3004 (2001).

13. M. M. Shakya and Z. Chang, Appl. Phys. Lett. 87, 041103 (2005). 